language (mainly English) after they enter secondary schools, though some city children may start to learn English in primary schools or even earlier. However, a problem arises when most students get to university, in that, seemingly, the more English they have acquired, the less able they are to communicate in the language. Although they can pass English examinations with good marks, they have difficulties in communication and sometimes cannot speak or write at all. The problem may be attributed to the students' motivation, their learning strategies and some cultural factors. This paper tries to make an analysis of the problems and the factors that affect their English language learning in order to find a way to help them to acquire linguistic and communication competence in the English language.

\section{Reading and writing}

01-436 Ashwell, Tim (Komazawa Junior Coll., Tokyo, Japan). Patterns of teacher response to student writing in a multiple-draft composition classroom: Is content feedback followed by form feedback the best method? Journal of Second Language Writing (Norwood, NJ, USA), 9, 3 (2000), 227-57.

In the study reported here, four different patterns of teacher feedback were given to foreign language students producing a first draft (D1), a second draft (D2), and a final version (D3) of a single composition. The pattern usually recommended within a process writing approach of content-focused feedback on D1 followed by form-focused feedback on D2 was compared with the reverse pattern, another pattern in which form and content feedback were mixed at both stages, and a control pattern of zero feedback. It was found that the recommended pattern of feedback did not produce significantly different results from the other two patterns in which feedback was given in terms of gains in formal accuracy or in terms of content score gains between D1 and D3. A post-hoc analysis of changes made by students revealed that they may have relied heavily on form feedback and that content feedback had only a moderate effect on revision. Explanations for these findings are put forward and the implications for the classroom are drawn.

\section{1-437 Biesenbach-Lucas, Sigrun (American} U., USA; Email: sblucas@american.edu) and Weasenforth, Donald. E-mail and word processing in the ESL classroom: how the medium affects the message. Language Learning and Technology (http://llt.msu.edu/), 5, 1 (2001), 135-65.

Computer-based media place new demands on language which can promote variations in language use (cf. Halliday, 1990). Electronic mail has assumed functions and formal features associated with spoken language as well as formal writing (Davis \& Brewer, 1997; Maynor, 1994; Murray, 1996). This has implications for language instructors: if e-mail does engender features of both written and spoken language, it is questionable that email writing will improve academic writing abilities. The present study attempts to provide insights into this issue. Non-native students in an intermediate pre-academic English as a Second Language (ESL) course responded to writing prompts using e-mail and word processing. Their writing was examined for (1) differences in use of cohesive features (Halliday, 1967; Halliday \& Hasan, 1976), (2) length of text produced in each medium, and (3) differences in text-initial contextualisation. Results indicate no obvious differences between students' e-mail and word-processed writing. However, the e-mail texts were significantly shorter than the word-processed texts, and text-initial contextualisation was more prominent in the word-processed than in the e-mail texts. The findings raise the question of whether e-mail benefits students in terms of acadenic writing development.

01-438 Flowerdew, Lynne. Using a genre-based framework to teach organizational structure in academic writing. ELT Journal (Oxford, UK), 54, 4 (2000), 369-78.

This article proposes the use of a genre-based framework, according to the Swalesian tradition of genre, for the teaching of the organisational structure of academic report writing. An analysis of 15 engineering undergraduate project reports reveals that the Problem-Solution pattern is prevalent in key sections of these reports, and should therefore also be considered as complementary to the notion of genre. Exercises for sensitising students to the genre structure and the Problem-Solution pattern are suggested. A case is also made for using good 'apprentice' models of student reports for devising genre-based exercises, on the grounds that they provide students with realistic, attainable models of academic writing.

01-439 Hyland, Fiona (Open U. of Hong Kong). Teacher management of writing workshops: two case studies. The Canadian Modern Language Review/La Revue canadienne des langues vivantes (Toronto, Ont.), 57, 2 (2000), 272-94.

Individual discussions or conferences offered to students in writing workshops are seen as a very valuable source of feedback. However, for such writing conferences to be effective, writing workshops need to be carefully planned and managed. This paper examines the approaches of two teachers to the management of writing workshops for English as a second/foreign language (ESL/EFL) students on an English proficiency course. The data come from a longitudinal study into the effects of feedback on ESL/EFL students and include questionnaire responses, interviews and classroom observations. The paper discusses the different procedures which the two teachers adopt in the management of their writing workshops and the effects that 
these differences have on the teacher/students and student/student interactions which take place in the workshops. It is suggested that these differences can be related to the teachers' beliefs about the role of feedback and the process of writing for ESL students. A number of pedagogical implications related to the management of writing workshops are also suggested.

\section{1-440 Khaldieh, Salim A. (Wayne State U.,} Detroit, Michigan, USA). Learning strategies and writing processes of proficient vs. less-proficient learners of Arabic. Foreign Language Annals (New York, USA), 33, 5 (2000), 522-34.

Previous research in second language (L2) learning indicates that successful learners seem to use a wider variety of learning strategies than unsuccessful learners. This article reports a study of learning strategies used by 43 American learners of Arabic as a foreign language $(\mathrm{FL})$ in their writing tasks, and gathered by a process of introspection. Analysis of the data shows that all learners were active users of different learning strategies to varying degrees. The less proficient writers, however, experienced a high level of anxiety and frustration, and adopted a negative attitude towards writing, in contrast to the more proficient writers who appeared to have controlled their anxiety level, and displayed more confidence. A closer examination of the linguistic system used in the writing task showed that the linguistic system and rhetoric of the first language (L1) prevailed. Translation of L1 structures was evident in the learners' writing samples. However, proficiency in writing seemed to be evolving; the attempt to create with and imitate L2 linguistic structures was obvious in the learners' essays. The article identifies the writing techniques and procedures used by learners of FL Arabic, as indicated by the learners' introspections, and concludes by discussing implications for classroom instruction.

\section{1-441 Kol, Sara and Schcolnik, Miriam (Tel}

Aviv U., Israel; Emails: sarakol@post.tau.ac.il; smiriam@post.tau.ac.il). Enhancing screen reading strategies. CALICO Journal (San Marcos, TX, USA), 18, 1 (2000), 67-80.

In an earlier pilot study, the present authors found that advanced English for Academic Purposes (EAP) students who were not experienced computer readers could neither scan nor skim texts effectively on screen. The present study hypothesised that if students were taught to use facilitating strategies, they would scan better from screen than from paper and also skim and close-read as well as they do on paper. Participants were 47 adult EAP students at the authors' institution. Throughout the semester, students in the experimental group were taught to use available on-line tools, and at the end of the semester a reading comprehension test was administered both to them and to the students in the control group. The results showed that, in all question types, students reading from screen performed as well as those reading from paper, confirming two of the three hypotheses.

\section{1-442 Lally, Carolyn Gascoigne (U. of}

Nebraska at Omaha, USA). First language influences in second language composition: the effect of pre-writing. Foreign Language Annals (New York, USA), 33, 4 (2000), 428-32.

Within what are seen as exciting and changing times for second language (L2) writing, a wealth of studies from those examining the effects of composition time constraints to inquiries into computer-assisted writing software - have taken place. According to the present author, one area which begs further investigation is the role played by the native language during the brainstorming or idea-generation stages of the L2 composing process. The study reported here sought to compare the effects of English language (i.e., the L1) brainstorming activities with similar activities conducted in French (i.e., the L2) in terms of their effects on the coherence of compositions drafted by intermediatelevel college French students.

01-443 Liou, Hsien-Chin (National Tsing Hua U., Taiwan, China; Email: hcliu@mx.nthu.edu.tw). The electronic bilingual dictionary as a reading aid to EFL learners: research findings and implications.

Computer Assisted Language Learning (Lisse, The Netherlands), 13, 4-5 (2000), 467-76.

This paper discusses the findings of a study on using recorded on-line data to investigate English as a Foreign Language (EFL) learners' strategies of word consultation in order to facilitate reading comprehension. The online logs were triangulated with off-line data which included the answers to reading comprehension and paraphrase questions, time on task, the selection of the word sense among its multiple definitions, and a questionnaire which surveys comparisons between the dictionary and other look-up facilities. It was found that learners with better language proficiency understood more, read faster, looked up fewer words and were able to disambiguate more polysemous words. Yet advanced learners are found to ignore some unknown words without looking them up while using more global strategies. Qualitative analyses showed some effective reading and word consultation strategies. Suggestions are put forward to shed light on how to tap the power of dictionary use for reading comprehension.

01-444 Marcoul, Isabelle (City U., London, UK; Email: i.marcoul@city.ac.uk). Creation of an electronic newspaper as a tool and experience to practise French writing composition. Francophonie (Rugby, UK), 22 (2000), 15-18.

This article describes the way in which a project to improve the writing skills and the technical French of 
English-speaking students in Computer Science developed into a student newspaper published on the World Wide Web. The students were involved at every stage in the analysis of their writing and their presentation. The results of an analysis of their work at surface level (grammar, vocabulary, sentence structures), meaning level and presentation level are discussed. It is suggested that this type of activity involves the students much more than traditional writing and leads to a different approach to and style of writing. Advice that the students found helpful, both in their writing and in composing their web pages, is given. The author found the project time-consuming but very rewarding, and argues that it is important to make use of a technology which is becoming more and more common.

\section{1-445 Sasaki, Miyuki (Nagoya Gakuin U.,} Japan). Toward an empirical model of EFL writing processes: an exploratory study. Journal of Second Language Writing (Norwood, NJ, USA), 9, 3 (2000), 259-91.

The study reported here investigated English as a Foreign Language (EFL) learners' writing processes using multiple data sources including their written texts, videotaped pausing behaviours while writing, stimulated recall protocols, and analytic scores given to the written texts. Methodologically, the study adopted a research scheme that has been successfully used for building models of Japanese first language writing. Three paired groups of Japanese EFL writers (experts vs. novices, more- vs. less-skilled student writers, novices before and after six months of instruction) were compared in terms of writing fluency, quality/complexity of their written texts, their pausing behaviours while writing, and their strategy use. The results revealed that (a) before starting to write, the experts spent a longer time planning a detailed overall organisation, whereas the novices spent a shorter time, making a less global plan; (b) once the experts had made their global plan, they did not stop and think as frequently as the novices; (c) second language proficiency appeared to explain part of the difference in strategy use between the experts and novices; and (d) after six months of instruction, novices had begun to use some of the expert writers' strategies. It was also speculated that the experts' global planning was a manifestation of writing expertise that cannot be acquired over a short period of time.

\section{1-446 Tarnopolsky, Oleg (Dnepropetrovsk}

State Technical U. of Railway Transport,

Dnepropetrovsk, Ukraine). Writing English as a

foreign language: a report from Ukraine. Journal of

Second Language Writing (Norwood, NJ, USA), 9, 3 (2000), 209-26.

This report investigates teaching writing in English in Ukraine. The past and present situations in teaching writing and the reasons for avoiding teaching commu- nicative writing skills in English courses in that country are considered. The results of Ukrainian English as a Foreign Language (EFL) students' needs analysis are presented, indicating the necessity of introducing writing into EFL courses. The process-genre approach is postulated as a foundation for elaborating an effective writing course for Ukraine, and the first version of the course based on such an approach is analysed. Causes of the failure of this course are reported. It is demonstrated that a successful EFL writing course has to be not only communicative but also state-of-the-art. To motivate students, it also has to involve them from the beginning level in activities, making writing itself fun. The second (successful) version of the course, with a great part of learning organised as writing for fun, is presented, and its advantages are shown.

01-447 Warden, Clyde A. (Chaoyang U. of Technology, Taiwan, Republic of China; Email: warden@mail.cyut.edu.tw). EFL business writing behaviors in differing feedback environments. Language Learning (Malden, MA, USA), 50, 4 (2000), 573-616.

This paper raises the question of the steps English as a Foreign Language (EFL) students go through when completing business-oriented English documents, and whether these steps can be differentially influenced by the type of feedback provided. To understand students' reaction to feedback, path analysis was used to generate models of student writing activity. Three groups received differing combinations of feedback and redrafting opportunity over four assignments. A total of 563 first drafts from 141 students were analysed, resulting in 5,630 data points for modeling. Results suggest that Taiwan business English writing students may implement proof-reading and self-directed redrafting behaviours aimed towards improving their writing when objective sentence-level error feedback is supplied with no opportunity for further correction. The addition of redrafting opportunity resulted in generally unproductive writing strategies but also lower objective error rates. Students receiving general teacher-based feedback exhibited redrafting behaviours and a tendency to copy directly from reference material.

\section{Language testing}

01-448 Alderson, J. Charles (Lancaster U., UK; Email: c.alderson@lancaster.ac.uk).Technology in testing: the present and the future. System (Oxford, UK), 28, 4 (2000), 593-603.

As developments in information technology have moved apace, and both hardware and software have become more powerful and cheaper, the long-prophe- 